\title{
Prevalence and Determinants of "No-Mobile" Phobia (Nomophobia) among University Students
}

\author{
AYOUB A. AL-SHAIKH, M.B.B.S.*; HASSAN M. ALMUSA, C.A.B.F.M.*; SAFAR A. AL-SALEEM, M.D.*; \\ FAISAL SAEED AL-QAHTANI, S.B.F.M.*; FATIMA RIAZ, Ph.D.*; RISHI K. BHATI, M.D.*; \\ SAAD AL-AMRI, M.B.B.S.**; AHMAD S. ASSIRI, M.B.B. S.**; SALEH A. AL-SHAIKHI, M.B.B.S.**; \\ ABDULHAKEEM A. AS SIRI, M.B.B.S.**; ABDULLAH A. AL-ARRAFI, M.B.B.S.**; \\ SAMI H.M. ALFAIFI, M.B.B.S.*** and OSSAMAA. MOSTAFA, M.D.* \\ Family \& Community Medicine Department, King Khalid University*, Family Medicine Resident, Ministry of Health** and \\ Family Medicine Specialist, King Khalid University Medical City***, Saudi Arabia
}

\begin{abstract}
Background: A simple random sample was followed to include the total required study sample at study colleges for both boys and girls. In each study college, the lists of students' names with their university IDs were used to select participant students. Selected students were personally contacted by the researcher, with the help of their tutors.

Aim of Study: To identify magnitude of "no-mobile phobia" (nomophobia) among Health Sciences students at King Khalid University, Abha, Saudi Arabia.

Subject and Methods: Following a cross-sectional study design, 625 health sciences colleges' students were included. A self-administered data collection study questionnaire was designed by the researchers, which included personal characteristics; mobile phone use: Duration of use of mobile phone, access to internet, average duration of daily use of the mobile phone, type of used mobile phone and the validated 20-item Nomophobia Questionnaire (NMP-Q).

Results: All participants had smartphones. Prevalence of nomophobia among students was $85.3 \%$, with $22.1 \%$ having severe nomophobia, and $63.2 \%$ having mild nomophobia. Students of applied medical sciences had the highest percentage of severe nomophobia, while students of medicine had the lowest percentage (35. $1 \%$ and $15.8 \%$, respectively). Nomophobia grades differed significantly according to study colleges $(p=0.003)$. Percentages of students with severe nomophobia were significantly higher among those who had internet access through their personal mobile phones $(p=0.017)$ and also among those who spend more than 2 hours daily with their mobile phones $(p<0.001)$. However, grades of nomophobia did not differ significantly according to students' gender, or Grade Point Average (GPA).
\end{abstract}

Conclusions and Recommendations: Mobile phone addiction is common among undergraduate students of Health Sciences Colleges at King Khalid University, Saudi Arabia.

Correspondence to: Dr. Ayoub A. Alshaikh,

The Department of Family \& Community Medicine, King Khalid University, Saudi Arabia
Health education of university students is necessary to prevent possible harmful effects of excessive use of mobile phones.

Key Words: Nomophobia- University students - Health Sciences Colleges - King Khalid University Saudi Arabia.

\section{Introduction}

THE "smartphone" is a mobile phone that can perform several computer functions [1]. Smartphones are currently the latest evolution of the mobile information and communication technologies [2], and the number of obtained mobile-cellular phones has exceeded the total number of the whole world population [3]

Smartphones are particularly popular among young adults. In fact, college students are regarded as the early adopters of smartphones [3]. The popularity of smartphones is attributed to the numerous features and daily tasks they can provide [4]. Although smartphones provide great benefits and help people satisfy their basic needs, it may also provoke several problems associated with smartphone use [я

The use of mobile phones has been reported to be associated that $44.4 \%$ of the medical students' headaches, decreased concentration, memory loss, hearing loss, and fatigue to the use of their mobile phones [6]. Moreover, pathological use of technology may exist in the form of techno-dependence [7], with a growing concern regarding problematic mobile phone use, and accordingly, it has been publicized extensively as an emerging social problem [8] 
Smartphones may cause compulsive checking habits [2], frequently leading to compulsive usage and increased distress, which can be addictive [3] Another problem exacerbated by smartphones is the "nomophobia", or mobile phone addiction, which is defined as "fear of being without smartphone" [9].

This study aimed to identify magnitude and risk factors of nomophobia among Health Sciences Colleges students at King Khalid University, Saudi Arabia.

\section{Subjects and Methods}

Following a cross-sectional design, this study was conducted in four Colleges of Health Sciences at King Khalid University (i.e., Colleges of Medicine, Dentistry, Pharmacy and Applied Medical Sciences) during the Academic Year 1438-1439H) 2017-2018.

A self-administered data collection tool was designed by the researchers. It comprised variables related to participants' personal characteristics and mobile phone use, in addition to the validated 20item "Nomophobia Questionnaire" (NMP-Q), where participants are expected to respond to a 7point Likert scale, with 1 being "Strongly Disagree" and 7 "Strongly Agree". For all 20 items, the NMPQ score was summed up. The total score for each participant was graded as "no nomophobia" (scores of <60), "mild nomophobia" (scores of 60-99), or "severe nomophobia" (scores $>$ - 100), i.e., mobile phone addiction [10]

To test the data collection tool, a pilot study was conducted on 30 university students, whose data were not included in the main study. This pilot study aimed to test the clarity of wording and items within the study questionnaire. The average duration for filling the questionnaire was about 3 minutes.

In this study, the minimum sample size has been decided according to Dahiru et al., [11], to be 600 students (out of a total of 1632 students at the four Health Sciences Colleges in King Khalid University). Therefore, the researchers considered a sampling fraction of (0.4), and a total of 650 Health Sciences students were invited to participate in this study.

A simple random sample was followed to include the total required study sample at study colleges for both boys and girls. In each study college, the lists of students' names with their university IDs were used to select participant students. Selected students were personally contacted by the researcher, with the help of their tutors.

After explaining the objectives and nature of the present study to invited students, a total of 625 students agreed to participate (i.e., response rate $=96.2 \%$ ).

The data self-administered questionnaire sheets were distributed to groups of participant students by the researcher at their colleges, during their break time between lectures. The researcher stayed with students to respond to their questions and to collected the filled questionnaire sheets immediately after being fulfilled.

The Statistical Package for Social Sciences (SPSS ver 25.0) was used for data entry and analysis. Descriptive statistics were calculated and the appropriate tests of significance (i.e., $\mathrm{X}^{2}$ ) were applied accordingly. Statistically significant differences were considered if $p$-values are less than 0.05 .

A written personal informed consent was asked from all potential participants prior to distribution of the data collection sheets. They were notified that their participation is completely optional. Collected data were kept strictly confidential and used only for research purposes.

\section{Results}

Table (1) shows that $74.7 \%$ of participant students aged $20-23$ years (73\% were males and $76.6 \%$ were females), while $9.4 \%$ were $<20$ years $(10.1 \%$ were males and $8.7 \%$ were females) and $15.8 \%$ were $>23$ years old $(16.9 \%$ were males and $14.7 \%$ were females). About one third of participants (37.4\%) were medical students $(34.4 \%$ were males and $40.8 \%$ were females), $29.6 \%$ were Dentistry students $(26.1 \%$ were males and $33.4 \%$ were females), $17.4 \%$ were Pharmacy students (19.9\% were males and $14.7 \%$ were females), while $15.5 \%$ were students of Applied Medical Sciences (19.6\% were males and $11 \%$ were females). About half of participants (51.4\%) had a GPA of 3.5-4.5 (50.3\% were males and $52.5 \%$ were females), while $17.6 \%$ had a GPA > 4.5 (18.1\% were males and $17.1 \%$ were females). All students had smartphones $(100 \%)$.

Table (2) shows that all participant students $(100 \%)$ had smartphones. The great majority of students $(84.8 \%)$ had access to internet their personal mobile phones $(86.5 \%$ were males and $82.9 \%$ were females) and most of them (52.5\%) use their 
mobile phones for more than 2 hours daily. There were no significant differences regarding use of mobile phones according to gender.

Table (1): Personal characteristics of study sample ( $n=625)$.

\begin{tabular}{lllllll}
\hline $\begin{array}{l}\text { Personal } \\
\text { characteristics }\end{array}$ & \multicolumn{2}{c}{$\begin{array}{c}\text { Males } \\
(\mathrm{n}=326)\end{array}$} & $\begin{array}{c}\text { Females } \\
(\mathrm{n}=299)\end{array}$ & \multicolumn{2}{c}{$\begin{array}{c}\text { Total } \\
(\mathrm{n}=625)\end{array}$} \\
\cline { 2 - 7 } & No. & $\%$ & No. & $\%$ & No. & $\%$ \\
\hline Age: & & & & & & \\
$\quad<20$ years & 33 & 10.1 & 26 & 8.7 & 59 & 9.4 \\
$\quad$ 20-23 years & 238 & 73.0 & 229 & 76.6 & 467 & 74.7 \\
$\quad>23$ years & 55 & 16.9 & 44 & 14.7 & 99 & 15.8 \\
College: & & & & & & \\
$\quad$ Medicine & 112 & 34.4 & 122 & 40.8 & 234 & 37.4 \\
$\quad$ Dentistry & 85 & 26.1 & 100 & 33.4 & 185 & 29.6 \\
$\quad$ Pharmacy & 65 & 19.9 & 44 & 14.7 & 109 & 17.4 \\
$\quad$ Applied Medical Sciences & 65 & 19.6 & 33 & 11.0 & 97 & 15.5 \\
Grade point average (GPA): & & & & & & \\
$\quad<3.5$ & 103 & 31.6 & 91 & 30.4 & 194 & 31.0 \\
$\quad$ 3.5-4.5 & 164 & 50.3 & 157 & 52.5 & 321 & 51.4 \\
$\quad>4.5$ & 59 & 18.1 & 51 & 17.1 & 110 & 17.6 \\
\hline
\end{tabular}

Table (2): Students' characteristics related to using their mobile phones.

\begin{tabular}{|c|c|c|c|c|c|c|c|}
\hline \multirow{2}{*}{ Characteristics } & \multicolumn{2}{|c|}{$\begin{array}{c}\text { Males } \\
(\mathrm{n}=326)\end{array}$} & \multicolumn{2}{|c|}{$\begin{array}{l}\text { Females } \\
(n=299)\end{array}$} & \multicolumn{2}{|c|}{$\begin{array}{c}\text { Total } \\
(\mathrm{n}=625)\end{array}$} & \multirow{2}{*}{$\begin{array}{c}p- \\
\text { value }\end{array}$} \\
\hline & No. & $\%$ & No. & $\%$ & No. & $\%$ & \\
\hline \multicolumn{8}{|c|}{ Having a smartphone: } \\
\hline Yes & 326 & 100.0 & 299 & 100.0 & 625 & 100.0 & 1.000 \\
\hline No & 0 & 0.0 & 0 & 0.0 & 0 & 0.0 & \\
\hline \multicolumn{8}{|l|}{$\begin{array}{l}\text { Internet access } \\
\text { through mobile: }\end{array}$} \\
\hline Yes & 282 & 86.5 & 248 & 82.9 & 530 & 84.8 & 0.216 \\
\hline No & 44 & 13.5 & 51 & 17.1 & 95 & 15.2 & \\
\hline \multicolumn{8}{|c|}{$\begin{array}{l}\text { Duration of daily } \\
\text { mobile use: }\end{array}$} \\
\hline$<1$ hour & 26 & 8.0 & 30 & 10.0 & 56 & 9.0 & 0.392 \\
\hline 1-2 hours & 121 & 37.1 & 120 & 40.1 & 241 & 38.6 & \\
\hline$>2$ hours & 179 & 54.9 & 149 & 49.8 & 328 & 52.5 & \\
\hline
\end{tabular}

Fig. (1) shows that prevalence of nomophobia among Health Sciences Colleges students was $85.3 \%$, with $22.1 \%$ having severe nomophobia, and $63.2 \%$ having mild nomophobia.

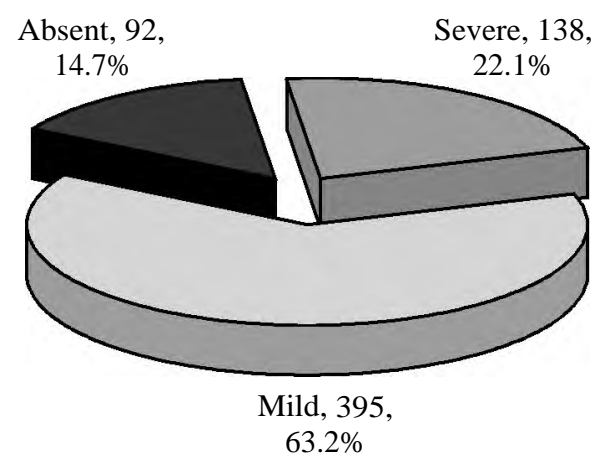

Fig. (1): Grades of "nomophobia" among undergraduate Health Sciences students.
Table (3) shows that older students ( $>23$ years) had highest percentage of severe nomophobia (24.2\%). However, nomophobia grades did not differ significantly according to students age groups. Male students had a higher percentage of severe nomophobia than females $(23.3 \%$ and $20.7 \%$, respectively). However, grades of nomophobia among students did not differ significantly according to their gender. Students of Applied Medical Sciences had the highest percentage of severe nomophobia while students of Medicine had the lowest percentage $(35.1 \%$ and $15.8 \%$, respectively). Nomophobia grades differed significantly according to study colleges $(p=0.003)$. Students with highest GPA had the least percentage of severe nomophobia (14.5\%). However, grades of nomophobia among students did not differ significantly according to their attained GPA. Percentages of students with severe nomophobia was significantly higher among those who have internet access through their personal mobile phones $(23.4 \%, p=0.017)$ and also among those who spend more than 2 hours daily with their mobile phones $(30.8 \%, p<0.001)$.

Table (3): Grades of nomophobia according to characteristics of participant students'.

\begin{tabular}{|c|c|c|c|c|c|c|c|}
\hline \multirow{2}{*}{$\begin{array}{l}\text { Personal } \\
\text { characteristics }\end{array}$} & \multicolumn{2}{|c|}{$\begin{array}{l}\text { Absent } \\
(n=92)\end{array}$} & \multicolumn{2}{|c|}{$\begin{array}{c}\text { Mild } \\
(\mathrm{n}=395)\end{array}$} & \multicolumn{2}{|c|}{$\begin{array}{l}\text { Severe } \\
(n=138)\end{array}$} & \multirow{2}{*}{$\begin{array}{c}p- \\
\text { value }\end{array}$} \\
\hline & No. & $\%$ & No. & $\%$ & No. & $\%$ & \\
\hline \multicolumn{8}{|l|}{ Age: } \\
\hline$<20$ years & 7 & 11.9 & 42 & 71.2 & 10 & 16.9 & 0.617 \\
\hline $20-23$ years & 73 & 15.6 & 290 & 62.1 & 104 & 22.3 & \\
\hline$>23$ years & 12 & 12.1 & 63 & 63.6 & 24 & 24.2 & \\
\hline \multicolumn{8}{|l|}{ Gender: } \\
\hline Male & 50 & 15.3 & 200 & 61.3 & 76 & 23.3 & 0.602 \\
\hline Female & 42 & 14.0 & 195 & 65.2 & 62 & 20.7 & \\
\hline \multicolumn{8}{|l|}{ College: } \\
\hline Medicine & 36 & 15.4 & 161 & 68.8 & 37 & 15.8 & 0.003 \\
\hline Dentistry & 25 & 13.5 & 123 & 66.5 & 37 & 20.0 & \\
\hline Pharmacy & 14 & 12.8 & 65 & 59.6 & 30 & 27.5 & \\
\hline Applied Medical Sciences & 17 & 17.5 & 46 & 47.4 & 34 & 35.1 & \\
\hline \multicolumn{8}{|l|}{$\begin{array}{l}\text { Grade point average } \\
(G P A) \text { : }\end{array}$} \\
\hline$<3$ & 29 & 14.9 & 122 & 62.9 & 43 & 22.2 & 0.248 \\
\hline $3-4$ & 43 & 13.4 & 199 & 62.0 & 79 & 24.6 & \\
\hline$>4$ & 20 & 18.2 & 74 & 67.3 & 16 & 14.5 & \\
\hline \multicolumn{8}{|l|}{$\begin{array}{l}\text { Internet access through } \\
\text { mobile: }\end{array}$} \\
\hline Yes & 70 & 13.2 & 336 & 63.4 & 124 & 23.4 & 0.017 \\
\hline No & 22 & 23.2 & 59 & 62.1 & 14 & 14.7 & \\
\hline \multicolumn{8}{|l|}{ Duration of daily mobile } \\
\hline \multicolumn{8}{|l|}{ use: } \\
\hline$<1$ hour & 16 & 28.6 & 36 & 64.3 & 4 & 7.1 & $<0.001$ \\
\hline 1-2 hours & 44 & 18.3 & 164 & 68.0 & 33 & 13.7 & \\
\hline$>2$ hours & 32 & 9.8 & 195 & 59.5 & 101 & 30.8 & \\
\hline
\end{tabular}




\section{Discussion}

Results of this study showed that all participant students had smartphones and most of them had Internet access through their mobile phones and were using their mobile phones for more than two hours daily.

These findings clearly indicate the high personal demand among university students toward using smartphones. Similarly, Alosaimi et al., [1], in Riyadh City, Saudi Arabia, reported that all students at King Saud University had smartphones, of whom $27.7 \%$ spent more than 8 hours daily with their smartphones. In USA, Lee [3], noted that use of mobile phones has almost reached the total world's population. College students are considered as the early owners of smartphones. Long et al., [12] reported that $99.2 \%$ of undergraduate students in China were smartphone users. Ndung'u and Waema [13] argued that growth of Internet and mobile phones usage has been exponential. Internet and smartphones have become the basic means of communication for all people regardless of their economic status and geographical location.

In addition, several studies also reported the increased use of smartphones by healthcare professionals in clinical settings [14,15], as well as for personal communication while working [16], which could be related to nomophobia behaviors [17] .

Our health sciences students had a high prevalence rate of nomophobia (85.3\%), where $63.2 \%$ had mild nomophobia and $22.1 \%$ had severe nomophobia. The high prevalence of severe nomophobia was also reported by several studies. Kanmani et al., [18] reported that prevalence of nomophobia among smartphone users was $98.8 \%$, where $41.6 \%$ had mild nomophobia, $42 \%$ had moderate nomophobia, and $15.2 \%$ had severe nomophobia. Sethia et al., [19] found that almost all undergraduate medical students had nomophobia, with $61.5 \%$ of students having moderate nomophobia, and $6.1 \%$ having severe nomophobia, while $32.1 \%$ had mild nomophobia.

In Navi Mumbai (India), about one third of secondary school students were mobile phone addicts [20] while prevalence of smartphone addiction among Chinese undergraduate students was $21.3 \%$, [11] and almost one fourth of resident doctors in north India had mobile phone dependence [21]

Findings of the present study showed that prevalence of severe nomophobia was highest among students more than 23 years old, and those of
Applied Sciences College, but least among medical students. It was also significantly higher among those who access internet through their personal mobile phones and those who spend more than two hours daily with their mobile phones. Moreover, severe nomophobia was slightly higher among male than female students, and it was higher among students with lower GPA.

The higher prevalence of mobile phone dependence among older students may reflect an increasing magnitude among university students that grows with their age, while being less among medical than other university students may describe the possible impact of relatively heavy study load among medical students, compared with those in other health sciences colleges.

The observed higher prevalence of mobile phone dependence among those who have Internet access within their smartphones and among those who spend more than two hours daily using their phones denote these are possibe risk factors for nomophobia.

Sethia et al., [19] reported that $48.9 \%$ of medical students were using their mobile phones for 2-4 hours per day, $21.3 \%$ used phones for 4-6 hours and $3 \%$ used mobile phones for more than 10 hours. Nevertheless, severity of nomophobia among medical students did not differ significantly according to their age, but differed significantly according to their daily duration of their smartphones. Moreover, Sethia et al., [19] and Prasad et al., [22] reported that severity of nomophobia among medical and dentistry students did not differ significantly according to their gender.

In China, Long et al., [11] found no significant differences in mobile phone addiction among undergraduate students according to their age or gender, but differed significantly according to students' colleges $(p=0.001)$, with highest prevalence among students of Science. They also found that mobile phone addiction differed significantly according to students' duration of daily use of mobile phones $(p<0.001)$, being highest among those who use their mobile phones for 4 hours or more daily.

In Riyadh, Saudi Arabia, Alosaimi et al., [1] found that gender was not significantly related to nomophobia scores. However, in Madrid, Spain, Sánchez-Martínez and Otero [22] reported that intensive mobile phone use among adolescent students was significantly associated with lower academic achievements. 
The present study concluded that smartphones are universally used by all undergraduate students of Health Sciences colleges at King Khalid University, Saudi Arabia, and nomophobia is common among them. Nomophobia is significantly higher among students of Applied Medical Sciences, those who access internet by their mobile phones and those who use their mobile phones for more than two hours daily.

Therefore, health education should be targeted to university students so as to prevent possible harmful effects of excessive use of mobile phones, including nomophobia. Undergraduate university students should be advised to use their mobile phones judiciously. Risk factors associated with mobile phone addiction should be considered in putting plans for future intervention activities to prevent and/or minimize nomophobia among undergraduate university students.

\section{Study limitations:}

This study followed a cross-sectional design, which is mainly useful for hypothesis generation, rather than hypothesis testing. Moreover, study participants were limited to colleges of health sciences at King Khalid University. Therefore, the generalizability of its findings should be cautiously considered.

\section{References}

1- ALOSAIMI F.D., ALYAHYA H., ALSHAHWAN H., AL- MAHYIJARI N. and SHAIK S.: Smartphone addiction among university students in Riyadh, Saudi Arabia Fahad D. Saudi. Med. J., 37 (6): 675-83, 2016.

2- OULASVIRTA A., RATTENBURY T., MA L. and RAITA E.: Habits make smartphone use more pervasive. Personal and Ubiquitous Computing, 16 (1): 105-14, 2013.

3- LEE S.Y.: Examining the factors that influence early adopters' smartphone adoption: The case of college students. Telematics and Informatics, 31 (2): 308-18, 2014.

4- PARK N., KIM Y.C., SHON H.Y. and SHIM H.: Factors influencing smartphone use and dependency in South Korea. Computers in Human Behavior, 29 (4): 1763-70, 2013.

5- KANG S. and JUNG J.: Mobile communication for human needs: A comparison of smartphone use between the US and Korea. Computers in Human Behavior, 35: 376-87, 2014.

6- KHAN M.M.: Adverse effects of excessive mobile phone use. Int. J. Occup. Med. Environ. Health, 21: 289-93, 2008.

7- BROD C.: Managing techno stress: Optimizing the use of computer technology. Pers. J., 61: 753-7, 1982.
8- MERLO L.J., STONE A.M. and BIBBEY A.: Measuring problematic mobile phone use: Development and preliminary psychometric properties of the PUMP scale. J. Addict. 2013: 912807, 2013.

9- ARCHER D.: Smartphone Addiction. Psychology Today, 2013. Website: https://www.psychologytoday.com/blog/ reading-between-the-headlines/201307/smartphoneaddiction. Last accessed on: January, 20 th, 2018.

10- DAHIRU T., ALIYU A. and KENE T.S.: Statistics in Medical Research: Misuse of Sampling and Sample Size Determination. Annals of African Medicine, 5 (3): 158 61, 2006.

11-YILDIRIM C. and CORREIA A.: Exploring the dimensions of nomophobia: Development and validation of a selfreported questionnaire. Computers in Human Behavior, 49: 130-7, 2015.

12- LONG J., LIU T.Q., LIAO Y.H., QI C., HE H.Y., CHEN S.B. and BILLIEUX J.: Prevalence and correlates of problematic smartphone use in a large random sample of Chinese undergraduates. BMC Psychiatry, 16: 408, 2016.

13- NDUNG'U M.N. and WAEMA T.M.: Development outcomes of internet and mobile phones use in Kenya: The households' perspectives. Info., 13 (3): 110-24, 2011.

14- CHO S. and LEE E.: Distraction by smartphone use during clinical practice and opinions about smartphone restriction policies: A cross-sectional descriptive study of nursing students. Nurse Educ. Today, 40: 128-33, 2016.

15- BAUTISTA J.R. and LIN T.T.: Sociotechnical analysis of nurses' use of personal mobile phones at work. Int. J. Med. Inf., 95 (1): 71-80, 2016.

16- McBRIDE D.L., Le VASSEUR S.A. and LI D.: Nonwork-related use of personal mobile phones by hospital registered nurses. JMIR mHealth uHealth, 3 (1): e3, 2015.

17- KAUR A. and SHARMA P.: A descriptive study to assess the risk of developing nomophobia among students of selected nursing colleges Ludhiana, Punjab. Int. J. Psyc. Nurs., 1 (2): 1-6, 2015.

18- KANMANI A., BHAVANI U. and MARAGATHAM R.S.: NOMOPHOBIA-An Insight into Its Psychological Aspects in India. Int. J. Indian Psychol., 4 (2): 5-15, 2017.

19- SETHIA S., MELWANI V., MELWANI S., PRIYA A., GUPTA M. and KHAN A.: A study to assess the degree of nomophobia among the undergraduate students of a medical college in Bhopal. Int. J. Community Med. Public Health, 5 (6): 2442-5, 2018.

20- NIKHITA C.S., JADHAV P.R. and AJINKYA S.A.: Prevalence of Mobile Phone Dependence in Secondary School Adolescents. Journal of Clinical and Diagnostic Research, 9 (11): VC06-VC09, 2015.

21- AGGARWAL M., GROVER S. and BASU D.: Mobile Phone Use by Resident Doctors: Tendency to AddictionLike Behaviour. German J. Psychiatry, 15 (2): 50-5, 2012.

22- PRASAD M., PATTHI B., SINGLA A., GUPTA R., SAHA S., KUMAR J.K., MALHI R. and PANDITA V.: Nomophobia: A Cross-sectional Study to Assess Mobile Phone Usage Among Dental Students. J. Clin. Diagn. Res., 11 (2): ZC34-ZC39, 2017. 


\section{مجددات رهاب (غياب الهاتف المحمول) بين طلاب الجامعة}

هدف الدراسة: تحديد حجم مشكلة رهاب (غياب الهاتف المحمول) (النوموفوبيا) بين طلاب العلوم الصحية بجامعة الملك خالد، أبها، المملكة العربية السعودية.

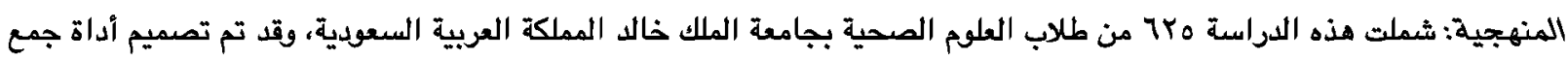
اللبيانات، والتى تضمنت الخصائص الشخصية، وإستخدام الهاتف المحمول وكذلك أستبيان النوموفوبيا (Nomophobia Questionnaire)

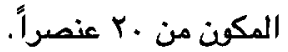

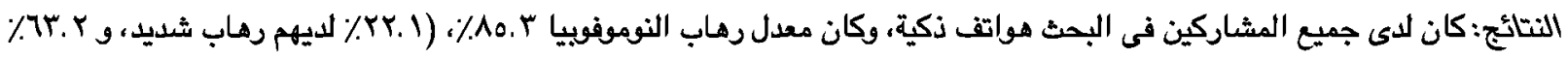

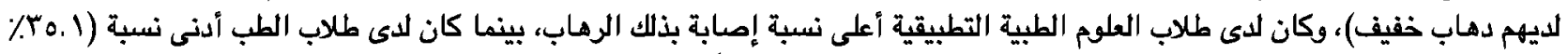

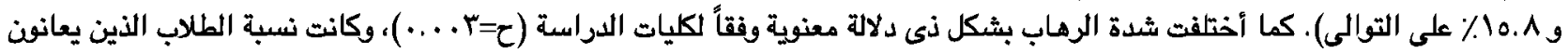

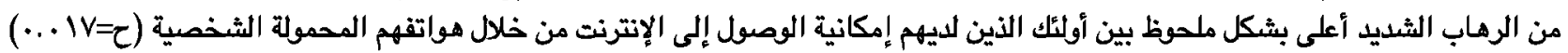

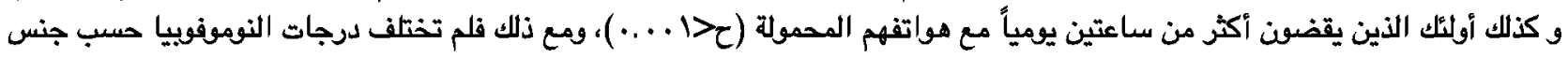

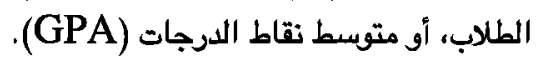

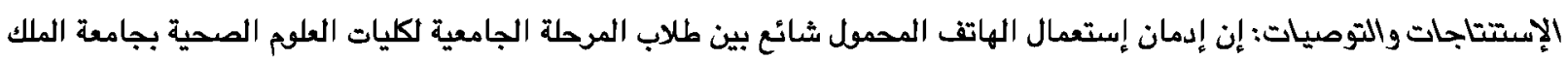

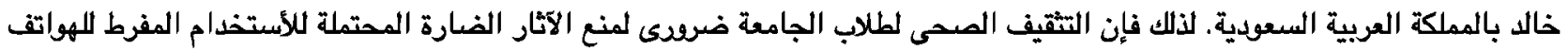

